\title{
C ONTRIBUTOR S
}

Keith Cicerone, Ph.D.

Center for Head Injury

Cognitive Rehabilitation Department

R.W.I. Lifestyle Institute

2048 Oak Tree Road

Edison, NJ 08820

John DeLuca, Ph.D.

Departments of Research and Psychology

Kessler Institute

1199 Pleasant Valley Way

West Orange, NJ 07052

Head Injury Interdisciplinary Special Interest

Group of the American Congress of

Rehabilitation

J. Preston Harley, Ph.D.

Director of Neuropsychology

Rehabilitation Medicine Clinic

26W171 Roosevelt Rd.

Wheaton, IL 60189-0389

Rajendra Jutagir, Ph.D.

Mount Sinai Medical Center

Department of Geriatrics and Adult

Development

1 Gustave L. Levy Place; Box 1070

New York, NY 10029-6574
James Malec, Ph.D.

Psychology

Department of Psychiatry and Psychology

Mayo Clinic (West-9)

Rochester, MN 55905

Sarah Raskin, Ph.D.

Good Samaritan Neuropsychological Services 1420 South Meridian

Suite A

Puyallup, WA 98371

Jack Rattok, Ph.D.

Transitions of Long Island

Rehabilitation for the Head Injured

1554 Northern Blvd.

Manhasset, NY 11030

Richard Waxman, Ph.D.

Mount Sinai Medical Center

Department of Rehabilitation Medicine

1 Gustave L. Levy Place; Box 1240

New York, NY 10029-6574

A complete listing of all authors of an article appears on the first page of each article. The above listing provides full mailing addresses for only the senior author of each article. 